\title{
O SNUC, A PRODUÇÃO DO CONHECIMENTO E AÇÃO RELATIVAS AO USO PÚBLICO E EDUCAÇÃO AMBIENTAL NO BRASIL (2014-2020)?
}

\author{
Júlio Konrath Deuner ${ }^{1}$
}

\begin{abstract}
Resumo: Este trabalho vem apresentar uma pesquisa multidisciplinar sobre a produção do conhecimento e ações de Educação Ambiental-EA vinculados ao uso público em unidades de conservação-UCs no Brasil, no período de 2014-2020, e discutir a relevância dessas práticas como estratégia de educação socioambiental 20 anos depois da instituição do Sistema Nacional de Unidades de Conservação. Para tal foi feita uma pesquisa qualitativa exploratória para coleta e pré-seleção do material. Os resultados obtidos demonstram que, com notáveis exceções de protagonismo local, as ações relatadas revelaram a fragilidade da regulamentação do uso público das UCs, a carência programas de visitação e linhas de atuação estruturadas em EA, não configurando uma política pública de democratização do uso público de áreas protegidas.
\end{abstract}

Palavras-chave: Uso Público de Áreas Protegidas; Educação Socioambiental; Conhecimento e Gestão de Ecossistemas Regionais.

Abstract: This work presents a multidisciplinary research on the production of knowledge and actions of Environmental Education-EA linked to public use in conservation units-UCs in Brazil, in the period 2014-2020, and discuss the relevance of these practices as a socioenvironmental education strategy 20 years after the establishment of the National System of Conservation Units. To this end, an exploratory qualitative research was carried out to collect and pre-select the material. The results obtained demonstrate that, with notable exceptions of local protagonism, the reported actions revealed the weakness of the regulation of public use of UCs, the lack of visitation programs and lines of action structured in EA, not configuring a public policy of democratization of public use protected areas.

Keywords: Public Use of Protected Areas; Socioenvironmental Education; Knowledge and Management of Regional Ecossystems

\footnotetext{
1Universidade Estadual do Rio Grande do Sul. E-mail: juliokonrath@hotmail.com. Link para o Lattes: http://lattes.cnpq.br/5104070607564496
} 


\section{Introdução}

Reconhecendo a finitude e a relevância das áreas naturais e seminaturais subtraídas ao desenvolvimento econômico, para manutenção dos processos ecológicos e da sustentabilidade planetária para as futuras gerações, a Lei Federal 9.985/2000, instituiu o Sistema Nacional de Unidades de Conservação da Natureza - SNUC no Brasil, tardiamente em relação a outras nações democráticas amercianas, muito embora estas já existissem como espaço público no nosso ordenamento territorial desde o final do Império (Figura-1). No seu Cap.II, Artigo $4^{\circ}$, Inciso XII, a dita Lei afirma como uma das suas prerrogativas "favorecer condições e promover a educação e a interpretação ambiental, a recreação em contato com a natureza e o turismo ecológico". As áreas naturais ao serem reconhecidas como Unidades de Conservação-UCs passam a integrar um conjunto de políticas públicas de conservação da natureza e Educação Ambiental - EA, porém, ainda é pouco comum por parte das instituições e órgãos executores dessas políticas, a busca de informações sobre as ações educativas em UCs desenvolvidas pelas redes de ensino a fim de intervir na realidade.

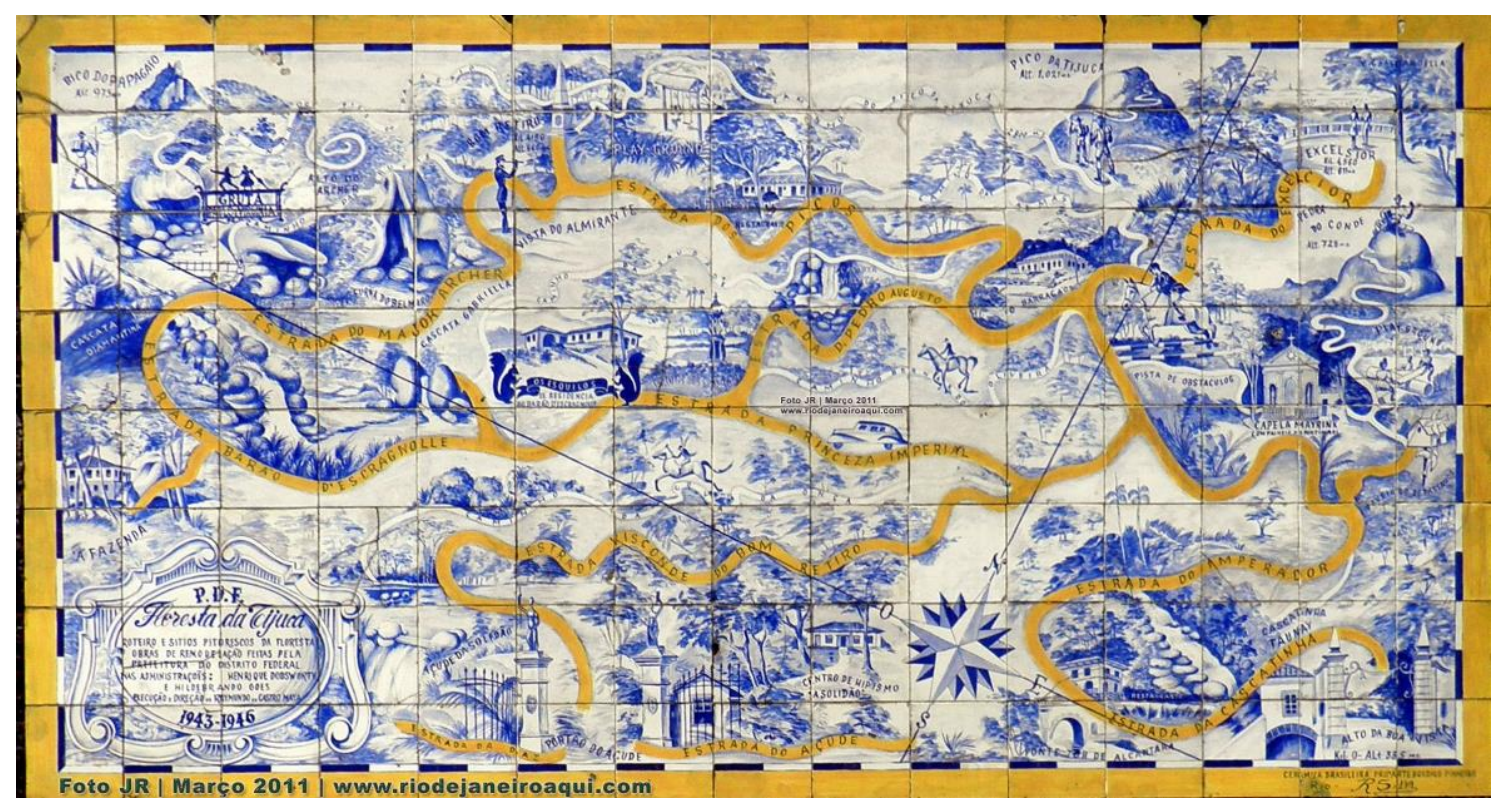

Figura 1: Mosaico de azuleijos ilustrativo do Mapa da Floresta da Tijuca (primeira área pública protegida instituída no Brasil por Dom Pedro II em 1861)

Fonte: Rio de Janeiro, 2011.

Revbea, São Paulo, V. 17, № 1: 247-270, 2022. 
educação pressupõem a Educação Ambiental - EA como um direito humano essencial, garantido pela vanguarda da legislação ambiental mundial expressa na nossa Constituição Federal (1988), no Artigo $2^{\circ}$. da Lei o 9.795 que instituiu a Política Nacional de Educação Ambiental no Brasil (1999) e nas Diretrizes Curriculares Nacionais de Educação Ambiental (2012), que estabelece que "a EA é um componente essencial e permanente da educação nacional, devendo estar presente, de forma articulada, em todos os níveis e modalidades do processo educativo, em caráter formal e não-formal".

Uma verdade básica por vezes ignorada por gestores públicos que convém lembrar, é que a EA é uma ação prevista em todas as categorias do SNUC do Brasil, porém até recentemente não havia uma definição das possíveis linhas de ação a serem seguidas para o desenvolvimento da EA em UCs. Estas somente passam a ser conhecidas a partir da Estratégia Nacional de Conservação e Educação Ambiental (2016) e das Diretrizes Nacionais de Interpretação Ambiental em UCs (2018). Embora o Brasil seja reconhecidamente pela Organização Mundial do Turismo como o país com maior número de atrativos turísticos relacionados às suas belezas naturais e socio biodiversidade, esse rico patrimônio natural e cultural ainda é desconhecido para os próprios brasileiros (BUENO, 2011; OECO, 2018).

O uso público ${ }^{2}$ de áreas protegidas (visitação, recreação, turismo ecológico, interpretação/Educação Ambiental e pesquisa científica) é um instrumento essencial para aproximar a sociedade da natureza e despertar a consciência da importância da conservação dos ambientes e processos naturais. Mesmo as UCs de proteção integral prestam-se à implantação de trilhas interpretativas para caminhantes, por ser uma atividade de uso indireto e de baixo impacto, se for realizada de forma ordenada e compatível com os objetivos de conservação e manejo dos recursos. Contudo, considerando apenas a categoria de área protegida mais antiga e numerosa, verifica-se que ainda há um número reduzido de Parques que dispõem de plano de manejo no Brasil e, consequentemente, de programas de visitação, interpretação ou Educação Ambiental (CANTO-SILVA; SILVA, 2017; RODRIGUES; CAMPANHÃO; BERNADI, 2018; RECH; PERELLO; CANTO-SILVA, 2018; DOS SANTOS; AZEVEDO, 2019).

A gestão de áreas naturais protegidas, especialmente nos países em desenvolvimento, deve reconhecer a importância da dimensão humana para o sucesso de qualquer estratégia de conservação dos ecossistemas, pois ao não possibilitar a visitação e não promover a EA estes espaços deixam de contribuir

\footnotetext{
2 Uso público: entendido aqui como o processo de uso do território e seus recursos através de atividades recreativas, turísticas, educativas, científicas ou culturais que promovam o usufruto e conhecimento público do patrimônio protegido.
} 
para o desenvolvimento sustentável, e de quem mais se espera que compreenda seu meio ambiente e colabore com a sua proteção - as comunidades locais. O paradoxo desse sonho/dilema da manutenção de espaços naturais públicos apartados do desenvolvimento, impõem uma gestão na perspectiva da educação socioambiental, isto é, voltada para formação de sujeitos capazes de compreender e intervir criticamente no seu contexto histórico e sociopolítico, no qual o gestor $<=>$ educador é desafiado a planejar, executar e avaliar processos de ensino-aprendizagem, que estimulem a participação pública na defesa da qualidade de vida, na gestão dos recursos ambientais e na conservação da biodiversidade.

A partir deste recorte político-pedagógico e epistemológico, cabe mapear e investigar o que essas ações vinculadas uso público de áreas protegidas no Brasil, no período de 2014 a 2020, apontam como caminhos a explorar e desafios à educação socioambiental nesses espaços públicos. Destarte, este trabalho de pesquisa teve por objetivo geral realizar uma pesquisa multidisciplinar acerca da produção do conhecimento científico e ação pública de EA associados à visitação de áreas protegidas no Brasil no período de 2014-2020, a fim de buscar responder a seguinte proposição: "em que medida as ações vinculadas ao uso público em áreas protegidas contribuem para educação na perspectiva da gestão socioambiental?"

Os objetivos específicos para tanto, foram: identificar quais são modalidades de publicação disponíveis sobre o tema; quais são as contribuições dessas pesquisas para o conhecimento das principais formas de uso público em áreas protegidas no Brasil; com quais os objetivos e regularidade são desenvolvidas propostas ou ações de Educação Ambiental vinculados às atividades de uso público nesses espaços; qual o perfil do público-alvo das ações de Educação Ambiental desenvolvidas; e qual a relevância dessas práticas como estratégia de conhecimento e gestão socioambiental de ecossistemas regionais.

O trabalho foi desenvolvido por meio de uma abordagem de pesquisa qualitativa (GIL, 2011) exploratória, realizada a partir de um levantamento bibliográfico multidisciplinar da produção científica e outras fontes de informação amplamente disponíveis, sobre pesquisas e ações educativas em EA sensu latu (formal, não-formal e informal) associadas à visitação em áreas protegidas no Brasil publicadas em revistas especializadas, em eventos na área/campo do conhecimento ou em mídias digitais, entre janeiro de 2014 e dezembro de 2020. A partir da coleta e pré-seleção das fontes de pesquisa bibliográfica foi realizada a leitura preliminar do material para identificação dos resumos com referência ao tema "uso público e Educação Ambiental em áreas protegidas", contendo menções explícitas no título, no resumo expandido e nas palavras-chaves. Após a identificação e leitura criteriosa dos trabalhos selecionados, foi realizada uma sistematização e análise exploratória descritiva das informações coletadas. Os resultados da pesquisa foram então organizados sob forma de fichas de leitura, elaboradas para a identificação de 
excertos dos textos que continham os elementos textuais de interesse (palavras, frases, expressões, parágrafos). Então, com base na análise descritiva e textual dos resultados obtidos e sua categorização foi possível tecer discussões e reflexões acerca dos principais aspectos relacionados ao tema de estudo.

\section{Desenvolvimento}

De acordo com a Estratégia Nacional de Comunicação e Educação Ambiental - ENCEA (2016), a consolidação das Unidades de Conservação UCs e da Educação Ambiental - EA são potências no processo de construção das políticas ambientais brasileiras, na medida que as UCs são espaços de articulação estratégica entre conservação, recreação e EA, como ponto de partida para gestão do uso público nesses espaços. E o ecoturismo é uma ferramenta capaz de fortalecer a apropriação das UCs pela sociedade, movimentar as economias locais e fomentar os recursos para a manutenção desses espaços. O uso público de UCs está diretamente associado ao processo de visitação, podendo se manifestar como atividades educativas, de lazer, esportivas, recreativas, científicas e de interpretação ambiental, que proporcionam ao visitante a oportunidade de conhecer, entender e valorizar os recursos naturais. De acordo com as Diretrizes Nacionais Visitação em UCs no Brasil (2007), o uso público de áreas protegidas deve pautar-se pelo princípio da visitação para o qual "a visitação é um instrumento essencial para aproximar a sociedade da natureza e despertar a consciência da necessidade da conservação dos ambientes e processos naturais".

Embora no Brasil o termo "áreas protegida" seja muitas vezes erroneamente empregado como sinônimo de Unidade de Conservação - UC, ambos não são a mesma coisa. De acordo com a Lei 9.985 que instituiu o Sistema Nacional de Unidades de Conservação - SNUC do Brasil (2000), o termo UC refere-se à um espaço territorial e seus recursos ambientais, incluindo as águas jurisdicionais, com características naturais relevantes, legalmente instituído pelo Poder Público, com objetivos de conservação e limites definidos, sob regime especial de administração, ao qual se aplicam garantias adequadas de proteção. Já o termo "área protegida" refere-se à uma variada gama de situações e espaços especialmente protegidos pela legislação ambiental brasileira (reserva legal, áreas de preservação permanente, faixa de servidão ambiental etc.), porém sem um estatuto ou diploma público dominial daquela área específica. Ainda segundo essa mesma Lei, o uso público de UCs está condicionado à providência de um Plano de Manejo, que é o documento técnico mediante o qual, com base nos objetivos gerais da UC, se estabelece seu zoneamento e as normas que devem gerir o uso da área, o manejo dos recursos naturais e as estruturas físicas necessárias à sua gestão. Este deve definir os programas de visitação que direcionem o uso público associado à conservação da natureza, respeitando as Instruções Normativas 
para a Prestação de Serviços Vinculados à Visitação e ao Turismo em UC Federais (2008) ou estaduais (2014).

A EA sensu lato conforme entendida por meio da Lei 9.795 que instituiu a Política Nacional de Educação Ambiental - PNEA do Brasil (1999), se constitui numa ferramenta de construção de "valores sociais, conhecimentos, habilidades, atitudes e competências voltadas para a conservação do meio ambiente, bem de uso comum do povo, essencial a sadia qualidade de vida e sua sustentabilidade". Ainda segundo a PNEA a EA deve ser promovida em todos os âmbitos e níveis de educação, em suas expressões formais (aquela desenvolvida nos currículos escolares, em todos os níveis de ensino, de forma multidisciplinar, integrada, contínua e permanente) e a EA não-formal (aquela relacionada a práticas de sensibilização e conscientização ambiental da sociedade como um todo).

Já a interpretação ambiental -IA possui características e definição conceitual que a diferencia da EA e a qualificam como uma ferramenta de gerenciamento do uso público em UCs, que supõem o envolvimento das comunidades locais no processo de planejamento e construção dos meios interpretativos, segundo as Diretrizes Nacionais de Interpretação Ambiental nas Unidades de Conservação (2018). Conforme originalmente concebida por Tilden (1957), a IA se nutre da informação e visa sensibilizar e mobilizar conteúdos afetivos e cognitivos nos visitantes, que permitam a reflexão e ação em favor do local visitado. Ela é o elo de comunicação entre o visitante e os recursos ambientais, e apesar de ser um instrumento educativo o objetivo prático da IA não é formar o indivíduo, nem consiste num processo contínuo, mas na realização de atividades com um público diversificado que permanece na área por um curto período e precisa ser sensibilizado com rapidez e eficiência (BORGES apud BUENO et al., 2011, p.172).

Considerando a realidade desencorajadora à conservação da biodiversidade encontrada no SNUC, visto que muitas UCs não dispõem de Planos de Manejo aprovados e/ou atualizados, e tampouco programas de visitação instituídos, e muitas sequer encontram-se abertas à visitação. Além disso, considerando que somente no período de 2007 a 2015, a visitação anual nos Parques Nacionais aumentou de cerca de três milhões de pessoas para quase sete milhões de acordo com o Instituto Chico Mendes de Conservação da Biodiversidade (2016), e desde então, esse número vem aumentado devido ao crescente interesse da população por atividades de recreação e turismo na natureza próximo aos grandes centros urbanos. Diante dos inúmeros impactos já conhecidos e documentados pela literatura científica no campo da ecologia da recreação ${ }^{3}$ (desenvolvimento de infraestrutura de recreação inadequado,

${ }^{3}$ Ecologia da recreação: estudo científico dos impactos ambientais que remonta às origens da prática de excursionismo e do movimento mundial pela criação de áreas protegidas no início do séc. XX, cujas pesquisas tomaram impulso a partir de 1970 com crescimento das ameaças aos ambientes naturais devido a popularização dos esportes ao ar livre.

Revbea, São Paulo, V. 17, № 1: 247-270, 2022. 
pisoteio excessivo e degradação de ecossistemas sensíveis, introdução de espécies exóticas invasoras, perturbações no equilíbrio da fauna e flora, a descaracterização da paisagem e cultura originais), como as áreas protegidas podem atender plenamente aos objetivos preconizados pelo SNUC, ou seja, não somente de conservação da biodiversidade e visitação pública, mas também de EA?

Partindo dessa problematização inicial, a forte tensão entre a complexidade temática deste tópico das ciências ambientais e sua consequente ação pública, representa um desafio extraordinário para realização de um ensaio bibliográfico "bom o bastante". Assim o propósito geral deste trabalho foi realizar uma revisão multidisciplinar abrangente das proposições, pesquisas e ações concretas de EA associadas ao uso público de áreas protegidas, de acordo com os critérios de seleção explicitados a seguir. Para tanto foi realizada uma revisão sistemática em bases de dados bibliográficos e repositórios eletrônicos de instituições acadêmicas, com auxílio das seguintes ferramentas de busca: Google acadêmico, Scielo, JSTOR e Google, utilizando como parâmetros de seleção: 0 ano de publicação, modalidade da publicação, o título da publicação, palavras-chave e resumo submetido. Além disso também foi feita uma consulta a páginas da internet de eventos redes de pesquisa e grupos temáticos.

As palavras-chave definidas como estratégia de busca incluíram os termos: "visitação", "recreação", "ecoturismo", "interpretação ambiental", "Educação Ambiental" "gestão socioambiental", "áreas protegidas ou unidades de conservação", sustentabilidade", "Brasil". Foram coletados 90 textos e hipertextos (artigos completos, resumos-expandidos, websites ou perfis públicos da internet) sobre o tema da pesquisa, que foram submetidos à uma pré-leitura do resumo, palavras-chaves e mais alguns trechos específicos, a fim de decidir se estes estavam relacionados ao tema principal da pesquisa, dos quais foram selecionados 27 documentos para leitura e análise textual aprofundada (Apêndice-1). Posteriormente, seis destes foram desconsiderados da análise textual, ou por não articularem as propostas teórico-metodológicas com atos pedagógicos extraclasse, ou não explicitarem suficientemente o delineamento científico dos procedimentos de coleta, análise e validação das ações de EA.

\section{Uso público e Educação Ambiental em áreas protegidas no Brasil}

Uma questão estruturante relacionada à instituição e gestão de UCs, é que a efetivação dos objetivos preconizados no Artigo 27 da Lei No. 9.985 que instituiu o SNUC (2000) afirma: "todas as UCs devem dispor de um Plano de Manejo, que irá orientar os programas de visitação e uso público nesses espaços". Contudo, é preciso estar consciente que pode haver incongruências entre as tendências político-pedagógicas expressas nos programas de 
visitação e IA/EA contidas nos planos de manejo de UCs, e as ações educativas executadas na prática. Uma pesquisa de opinão recente do IBOPE encomendada pela Wolrd Wildlife Foundation Brasil (OECO, 2018), sobre o que pensam os brasileiros sobre áreas protegidas e o meio ambiente, demonstrou que nove em cada 10 brasileiros gostariam de ter mais contato com a natureza nas cidades onde vivem e oito em cada dez valorizam lugares que possuem paisagens naturais quando vão viajar. De acordo com a mesma pesquisa, $91 \%$ dos entrevisados reconhecem que este valoroso patrimônio nacional não está sendo adequadamente protegido e para $66 \%$ dos brasileiros e tarefa é uma responsabilidade de todos os cidadãos.

A análise exaustiva dos últimos três relatórios (2015-2018) dos encontros da Comunidade de Prática ${ }^{4}$ de Visitação em Áreas Protegidas (EUA/BR) realizada por Pimentel (2019), demonstrou que apesar do consenso que a academia pode e deve desenvolver pesquisas em UCs, cresce a ideia que esta não consegue "dar respostas" frente à dimensão das questões que se impõem à gestão pública. Segundo esse autor, os tópicos com maior demanda quanto às linhas de atuação da comunidade estão relacionados a avaliação e manejo de impactos da visitação, e dentre os temas prioritários para atuação conjunta entre pesquisadores e gestores não houve aprofundamento sobre as ações de IA e EA. De acordo com Canto-Silva e Da Silva (2015), nota-se um visível crescimento no número de visitantes em áreas protegidas no Brasil a partir da primeira década do séc. XXI. Em metade (46,88\%) dos parques nacionais e estaduais estudados por estes autores até 2014, o número de visitantes foi superior a 10.000 por ano, já nos parques municipais foi inferior a 1.000 visitantes por ano. Desde então, o Parque Nacional da Tijuca (PNT), que é a UC que mais recebe visitantes por ano no Brasil, vem ultrapassando a frequência anual de três milhões de visitantes. Além disso, a perspectiva de estruturação de uma Rede Brasileira de Trilhas de longo curso - RBT, resultante de uma inédita ação conjunta dos Ministério do Meio Ambiente e do Turismo (2018) destinada a promover a visitação de UCs brasileiras por meio de caminhadas autoguiadas atestam a sua crescente visibilidade.

Segundo De Omena e Bregolin (2020), a implantação da RBT por meio dos seus seis eixos regionais, apontou um avanço de $350 \mathrm{~km}$ de trilhas implantas em 2016 para $1.900 \mathrm{~km}$ em 2018. Apesar do crescente aumento de voluntários envolvidos pela RBT, a aproximação entre gestores de UCs das três esferas governamentais e a incorporação das trilhas de longo curso como um novo produto turístico por operadoras de turismo constatados por estes mesmos autores, percebe-se que a divulgação das práticas educativas de EA desenvolvidas nas UCs brasileiras ainda é insatisfatória. Mas, como nos

\footnotetext{
${ }^{4}$ Comunidade de prática: conforme definido por Etienne Wenger (1998), o termo é entendido como um grupo de pessoas com interesses comuns, que se reúne regularmente para fins de parcerias de aprendizado e aplicação do conhecimento com foco compartilhado.
} 
lembram Canto-Silva e Da Silva (2015), 55,4\% dos parques cadastrados no SNUC até 2015 não disponibilizaram informações sobre proposta ou prática voltadas à $E A$, dos quais $33,42 \%$ estavam abertos à visitação. Segundo estes mesmo autores a maioria dos parques, em qualquer esfera administrativa considerada, não apresentava Plano de Manejo.

Já de acordo com Dos Santos e Azevedo (2019), a divulgação pública realizada pelos parques cadastrados no SNUC. ainda visa sobretudo à promoção do ecoturismo, sendo que dos parques que fizeram alguma divulgação explícita (eventos, fotos e descrição dos projetos), 44\% não ofereciam nenhuma informação sobre suas possíveis atividades de EA e $25 \%$ apresentam apenas indícios de prováveis atividades de EA. Segundo estes mesmo autores, 25,67\% dos parques cadastrados no SNUC até 2018 não apresentavam plano de manejo, sendo que $76 \%$ dos 50 parques abertos à visitação apresentam alguma proposta voltada à IA no seu plano de manejo. De acordo com Rech, Perello e Canto-Silva (2018) oito dos doze parques estaduais sul-rio-grandenses que contavam com planos de manejo, apenas um se encontrava efetivamente aberto à visitação e outros seis parques eventualmente recebiam visitas escolares para práticas de EA formal na ocasião do estudo. Segundo estes mesmos autores, a análise dos planos de manejo revelou que as principais ações em relação ao uso público que figuravam nos planos foi a produção de materiais educativos e a realização de palestras para escolas do entorno, já a necessidade de capacitação de recursos humanos para atuar na visitação não apareceu com prioridade nesses documentos.

Contrastando com o cenário de visitação em UCs públicas descrito anteriormente, de acordo com Corrêa, Foleto e Costa (2020) das 56 Reservas Particulares do Patrimônio Natural - RPPNs Federais existentes no Bioma Mata Atlântica, cadastradas no SNUC, apenas três $(0,05 \%)$ não dispunham de plano de manejo, 15 (26,7\%) não estavam abertas à visitação pública e $38(67,8 \%)$ apresentavam plano de manejo ou programa de visitação. Segundo estes autores, os principais meios interpretativos empregados nas RPPNs Federais foram trilhas interpretativas (59\%), Centros de IA (19\%) e atividades de capacitação (11,0\%). Embora a bibliografia consultada não apresente uma consolidação equivalente das informações a respeito dos principais meios interpretativos utilizados nas UCs públicas, infere-se que estes não difiram da situação observada nas UCs privadas.

\section{A educação socioambiental na gestão de unidades de conservação}

O desenvolvimento histórico da EA é marcado por uma profusão de concepções e práticas de EA em disputa no Brasil, associado às condições que contribuíram para o seu protagonismo mundial na área ambiental e nos movimentos sociais que convergiram para sua institucionalização como um 
campo do saber e política pública (LOUREIRO; SAISSE, 2014). Segundo esses mesmos autores, a perspectiva político-pedagógica que adota a postura histórico-crítica, também chamada de "EA socioambiental" é problematizadora das questões ambientais, se preocupa em investigar a realidade do público envolvido e o contexto de implantação da área protegida, como esta afetou as comunidades do entorno e os eventuais conflitos dos atores sociais com este espaço público.

De Oliveira (2011 apud DE OLIVEIRA et al, 2014) analisando as propostas de EA associadas aos órgãos responsáveis pelo SNUC no Brasil até 2011 relativamente àquelas praticada no Geoparque ${ }^{5}$ Naturtejo-PT constatou um direcionamento da EA para aqueles que visitam as UCs como turistas e a ausência de programa programas de EA direcionados à população local. Segundo os mesmos autores, muitas escolas inseridas no entorno de UCs não dispunham de programas de informação e comunicação de suporte às ações de EA na escola, e as escolas que realizavam ações educativas trabalhavam a EA na perspectiva do uso (restrições) dos recursos.

Rodrigues, Campanhão e Bernardi (2018) analisando as linhas de pensamento norteadoras das ações de EA não-formal propostas por Sauvé (2005) contidas nos planos de manejo dos Parques estaduais Paulistas, verificaram que apenas metade dos parques que contavam com planos aprovados até 2014, e embora 56,25\% destes apresentaram elementos da macrotendência de EA Pragmática e 50\% apresentaram elementos da macrotendência de EA Crítica, $100 \%$ dos planos continham propostas e ações da macrotendência de EA Conservacionista, confirmando resultados obtidos por Dias (2015, apud RODRIGUES; CAMPANHÃO; BERNARDI, 2018) e distinguindo-se dos obtidos por Layargues e Lima (2014) e Valenti et al (2012 apud RODRIGUES; CAMPANHÃO; BERNARDI, 2018) que apontaram as linhas Crítica e Pragmática como tendências dominantes.

Rech, Perello e Canto-Silva (2017) analisando os planos de manejo dos parques estaduais sul-rio-grandenses verificaram que estes expressaram elementos da macrotendência da EA Crítica, porém muitos limitaram-se a elencar ações de cunho basicamente conservacionista (palestras informativas, o manejo das trilhas, fortalecimento do ecoturismo). O exame de 20 trabalhos oriundos de 10 estados brasileiros contendo preleções em trilhas interpretativas por Pedrini (2018), revelou falhas importantes das preleções quanto aos seus parâmetros técnicos, tais como: a caracterização interpretativa das trilhas focada na geo e bio diversidades, a problematização histórico-crítica

\footnotetext{
${ }^{5}$ Geoparque: compreende um território delimitado, mas não sob a posse do Estado, integrante de uma estratégia de conservação do patrimônio geológico, biológico e cultural, que visa a melhoria das condições de vida humana sem exigir a exclusão total ou parcial daqueles que ali habitam.
} 
inexistente ou insuficiente das causas e consequências socioambientais, e a falta de avaliação da efetividade da retenção da IA. De acordo com esse autor, a fim de cumprir o objetivo de provocar e conduzir a aprendizagem sobre natureza, as ações de IA associadas à visitação pública em UCs no Brasil, precisam adotar um delineamento minimamente científico dos atos pedagógicos extraclasse e definir temas adequados a diferentes perfis de visitantes.

Fazendo agora uma análise interpretativa das pesquisas e ações práticas de EA realizadas em UCs, são enfocados a seguir os principais trabalhos que foram selecionados para o presente estudo. O Parque Nacional da Tijuca -PETj é a UC que mais recebe visitantes/ano no Brasil e desde 2014 vem ultrapassando a frequência anual de três milhões de visitantes. Para Braga, De Meirelles e De Siqueira (2017) embora os resultados da pesquisa sobre concepções e práticas dos visitantes sinalizem a relevância de ações educativas para mudança de conceitos e comportamentos em relação à natureza, a avaliação da efetividade das ações de EA desenvolvidas em trilhas interpretativas demonstrou que estas se restringiram ao âmbito comportamentalista (conservacionista) e não favorecem a visão crítica dos sujeitos a respeito da dinâmica social na qual estão inseridos. Outro estudo realizado no PETj visando analisar a contribuição das trilhas interpretativas na formação de estudantes de Tecnologia em Gestão Ambiental do CEFET-RJ (2016) expôs um fato inquietante, quando perguntado aos estudantes sobre o hábito de percorrer trilhas, descobriu-se que exceto para um dos estudantes, todos demais haviam percorrido no máximo de uma a três por toda a vida (!). Considerando que boa parte desses estudantes são provenientes da região do maior cluster de UCs situado em plena área urbana do país, essa situação evidencia 0 déficit de atividades extraclasse e experiências natureza oportunizadas pelas escolas de Ensino Básico e uma profunda contradição do próprio sistema de ensino profissionalizante.

Numa série de considerações político-pedagógicas e epistemológicas sobre a "abordagem socioambiental" das linhas de ação pedagógica em EA, com base em mais de 15 anos de experiências da Univalli - Joenville-SC na condução de visitantes em trilhas interpretativas, Munhoz et al. (2019) expõem que as preleções interpretativas realizadas em trilhas monitoradas, organizadas em torno de temas geradores e vivências lúdicas, promovem a "sensibilização dos visitantes para conservação" do bioma Mata Atlântica. Ainda segundo os autores, a fidelização de escolas ao programa indica que as trilhas monitoradas passaram a fazer parte da metodologia de ensino-aprendizagem. Todavia, os autores não fazem uma efetiva articulação teórico-prática com o referencial assumido, nem apresentam uma descrição suficiente do delineamento científico dos atos-pedagógicos e da avaliação da aprendizagem e/ou atitudes dos visitantes. 
Outro estudo nessa direção identificou 28 escolas no entorno do Parque Estadual de Itapuã-RS que visitaram a UC entre 2016 a 2018. Segundo Frizzo, Gonçalves e De Souza (2019), embora as atividades promovidas pela UC tenham conseguido atrair as escolas da região, por vezes observou-se uma discrepância entre os objetivos da UC os interesses de visitação das escolas (confraternização e lazer), pois os estudantes não vinham devidamente preparados para as trilhas e tampouco orientados quanto às atividades complementares, e ao serem questionados sobre as possíveis razões disso muitos professores admitiram não sentir-se preparados para promover as devidas conexões curriculares da visita com ações de EA extraclasse.

Conforme evidenciado por Pereira, De Souza e Linhares (2016), o plano de aula interdisciplinar sobre o bioma Mata Atlântica desenvolvido por esses autores com estudantes do Ensino Médio de uma escola pública (Ensino Médio) do entorno do Parque Estadual do Desengano - RJ, é um retrato emblemático dos inúmeros desafios encontrados pela escola e do papel do protagonismo individual no sentido de articular transversalmente conteúdos curriculares com as interrelações ecossistêmicas do ambiente em atividades extraclasse.

A título de uma ação de "ecoturismo pedagógico" com estudantes do Ensino Básico (EF/EM) de bairros vizinhos ao Parque Natural Municipal do Morro do Osso, em Porto Alegre-RS, Da Silveira, Jobin e Prochnow (2017) descrevem a realização de uma ação de conscientização ambiental a partir da condução em trilha interpretativa. Para isso os autores fazem uma proficiente caracterização interpretativa do percurso e apresentam uma carta-imagem de geolocalização da trilha interpretativo, raramente observada nos trabalhos desenvolvidos nessa linha, considerando que a existência de infraestruturas de apoio à visitação exige recursos técnicos e financeiros escassos e exercem um impacto ambiental não desprezível em UCs. Portanto, a caracterização de marcos interpretativos da geo biodiversidade do território, é uma fonte de informação de extrema relevância para futuros atos pedagógicos extraclasse por meio de trilhas interpretativa em UCs.

A construção de uma trilha autoguiada no Parque Natural Municipal João Alberto Xavier da Cruz -PNMJ, em Carazinho-RS, relatada por Shú, Martinez e Gerhard (2020), ilustra o único trabalho que tratou de um aspecto fundamental para o êxito de ações de visitação e IA na gestão de áreas protegidas - o planejamento e construção de trilhas interpretativas -, e conseguiu o mérito de incorporar aspectos da dinâmica social e da gestão participativa na experiência de construção da trilha. Segundo estes autores o envolvimento da comunidade local no processo de planejamento e construção dos meios interpretativos foi fundamental para o reconhecimento do parque como patrimônio natural e histórico, a conscientização quanto aos problemas de gestão deste e a "educação patrimonial" dos munícipes.

Um instigante experimento pedagógico sobre como o conhecimento do ambiente pode ser performado por meio de trilhas, utilizando a Teoria do AtorRevbea, São Paulo, V. 17, № 1: 247-270, 2022. 
Rede como ferramenta de análise, foi realizado por Dos Santos, Silva e Kato (2017) com estudantes do 6ㅇ. Ano (Ensino Fundamental) de uma escola pública na Estação Ecológica da UFMG. Segundo seus autores, o experimento permitiu identificar a trilha como um "actante" focal no qual o condutor ambiental exerce um importante papel de mediador/transformador do conhecimento que ele transporta e das relações entre os componentes da rede. Por outro lado, também evidenciou lacunas socioeducativas (falta de afetividade, flexibilização do roteiro) na formação dos condutores ambientais.

Na pesquisa participante envolvendo uma sequência-didática seguida de trilha interpretativa com os visitantes do Parque Estadual do Utinga - PEUt, realizada por Da Silva e Silva (2017), os autores ressaltam que embora todos sujeitos da pesquisa reconheçam o PEUt como um espaço pertencente à coletividade e a importância da EA para a qualificação da percepção ambiental da comunidade, a realidade educacional vivenciada no Projeto de Educação Ambiental Saneamento e Cidadania da Cia de Saneamento do Pará negligencia aspectos socioambientais imprescindíveis à gestão pública. Pois, segundo os autores, durante todas as etapas da pesquisa não se observou nenhuma crítica à indústria poluidora dos rios, ao agronegócio que extermina ecossistemas inteiros e contamina o subsolo com agrotóxicos, não proferiu uma só palavra quanto à pobreza e o papel do Estado no tocante às políticas públicas.

$\mathrm{Na}$ análise do Programa Parque-Escola feita por Chaves et al (2015), estruturado a partir de um diagnóstico realizado em 22 escolas municipais pelo Setor Educação Ambiental de Guapimirim-RJ, visando estimular a inserção das UCs como temática da EA no ensino formal após constatar a deficiência destas quanto ao uso público das UCs do entorno, os autores discutem uma série de ações de EA, não-formal e conservacionista, enfatizando o uso de trilhas interpretativas na transformação das representações ambientais dos visitantes. Chama atenção, porém, que na observação das interações dos grupos com as trilhas os autores constataram um comportamento que não diferiu entre os grupos atendidos (servidores municipais, professores, estudantes e visitantes): o "desconhecimento" de recomendações básicas para realização de caminhadas interpretativas - atenção e silêncio - indispensáveis à $\mathrm{IA}$ em contato com a natureza.

$\mathrm{Na}$ experiência do curso de capacitação de condutores ambientais, promovido pela UEMG-Campus de Passos para estudantes do $3^{\circ} \mathrm{Ano}$ (Ens.Méd.) de uma escola pública do entorno do Parque Nacional da Serra da Canastra-MG, Matos, Ferreira e Zampieron (2017) relatam que ao serem questionados pelos ministrantes quanto à falta de interesse da população local pelo parque, os cursistas atribuíram o desinteresse ao fato do Parque constituir-se aparentemente num "lugar comum" devido a sua proximidade com a comunidade. Porém, segundo os autores, essa impressão oculta uma verdade inconveniente: embora os cursistas percebam benefícios concretos da 
criação do Parque (preservação de espécies ameaçadas de extinção e o reconhecimento ecoturístico no nacional, geração de renda), estes admitem que a categorização de uso restrito da UC configura dificuldades permanentes para gestão de conflitos na região (queimadas intencionais, passivo de indenizações fundiárias, queda da atividade pecuária). Num movimento contrário a esse estado das coisas, percebido por uma visão que ignora a verdade auto evidente da ausência de ações que incentivem a aproximação da comunidade com o parque, o referido curso capacitou e certificou 15 condutores ambientais que passaram a atuar no parque.

A constituição de espaços dedicados à formação e capacitação continuada em EA, sob forma de redes locais/regionais, pautada no $1^{\circ}$ Encontro Estadual Educação e Ambiente - RS (REINHER apud BINKOWSKI et al., 2017), tais como a Rede Araucárias instituída a fim de desenvolver ações de $E A$ em Rede e apontar alternativas às questões socioambientais na região dos Campos de Cima da Serra, contribui para experiências inovadoras em políticas públicas de conservação e EA, tais como: Rede SEIVA - Socialização, Identidade, Vida e Ambiente: Educação Ambiental em Unidades de Conservação (MARQUES, 2017), "Projeto Intervenções socioambientais em UCs da região dos Campos de Cima da Serra" (ENGERS; COMUNELLO; KONRATH, 2019; ENGERS; KONRATH, 2021) e o Programa Geoparque Cânions do Sul (REDE ARAUCÁRIAS, 2020). Entre os aspectos que diferenciam a EA praticada em áreas protegidas sob a forma de Geoparques e Reservas Mundiais da Biosfera chanceladas pela Organização das Nações Unidas pela Educação Ciência e Cultura - UNESCO, de áreas protegidas sob forma de sistemas nacionais de UCs reconhecidos pela União Internacional pela Conservação da Natureza - IUCN, é que àquelas não pressupõem a exclusão total ou parcial do homem como estas. O trabalho colaborativo e contínuo das equipes técnicas com a comunidade e professores das escolas do entorno dessas áreas, visando a conexão entre os conteúdos curriculares e os problemas socioambientais e os elementos do ambiente local com significado para os estudantes desenvolvidos em Geoparques são práticas ainda incipientes no Brasil.

No compromisso global com a conservação da biodiversidade in situ firmado na Convenção Mundial da Diversidade Biológica (1993), mais de 160 países acordaram em proteger pelo menos $17 \%$ da superfície continental e $10 \%$ da superfície marinha territorial, por meio da instituição e implementação de Sistemas Nacionais de Unidades de Conservação. Embora oficialmente o Brasil tenha alcançado o patamar mínimo de proteção de ecossistemas terrestres em UCs, a proteção e o manejo sustentável dessas áreas enfrentam imensos problemas para conservação da biodiversidade na prática (PROCHNOW, 2018; WWF, 2018).

Outrossim, se cada município o Brasil, e quiçá do Planeta, garantisse a proteção e recuperação dos ecossistemas naturais do seu território, na mesma proporção em que são convertidos ou degradados pelas atividades 
econômicas, sequer precisaríamos de sistemas nacionais ou convenções multilaterais para instituir metas ecopolíticas de conservação da biodiversidade. Conforme apontado pelos diversos autores que se ocuparam do tema em tela, a mantuenção de um Sistema Nacional de Unidades de Conservação viável passa pela necessária democratização do seu uso público e a EA da sociedade em todos os níveis e modalidades de ensino. Estas, porém, são realidades muito distantes e não configuram políticas públicas efetivas. Diante das condições para visitação pública e do cenário exposto quanto a EA em áreas protegidas no Brasil descrito, cabe aos políticos, gestores, professores, pais e a todos cidadãos enquanto educadores ambientais a seguinte reflexão "como estamos educando nossos jovens a conviver com a natureza?"

Esperamos que a leitura exaustivo ensaio bibliográfico tenha contribuido para iluminar um pouco mais nosso caminho em direção à um melhor futuro imaginado. Nesse sentido, com a intenção de sumarizar essa contribuição, seguem algumas ações emergenciais apontadas pelos diversos autores que poderiam ser aplicadas em UCs do Brasil:

- Exigir que as UCs cadastradas no SNUC, desprovidas de planos de manejo ou programas de visitação aprovados, viabilizem seus Planos Emergenciais de Uso Público, a fim de garantir que estejam abertas à visitação;

- Condicionar a aplicação de instrumentos econômicos (ICMS-ecológico, compensão ambiental e pagamento por serviços ambientais) à implementação de programas de voluntariado de apoio à gestão de UCs, em unidades federativas com insuficiência de recursos financeiros e técnicos;

- Fomentar ações de ensino, pesquisa e extensão que articulem teorias de aprendizagem com ações pedagógicas extraclasse e capacitação proffisional com jovens e adultos das comunidades do entorno de UCs;

- Otimizar o uso dos recursos de informação e comunicação ambiental (geoinformação, biogeografia e ecoturismo) em atividades preparatórias à visitação adaptados às necessidades dos visitantes;

- Empregar procedimentos científicos de planejamento e avaliação da efetividade da condução de visitantes e de monitoramento de impactos da visitação pública em UCs;

- Desenvolver ações continuadas junto às escolas e comunidades locais, voltadas ao trabalho colaborativo da equipe gestora da UC com esses atores, visando a democratização do conhecimento da rica socio biodiversidade brasileiras; e incentivar o compartilhamento de saberes através de redes de informação e comunicação, e comunidades de prática em EA e Gestão socioambiental; 


\section{Conclusões}

A busca de informações no período abrangido nesta pesquisa revelou a falta de publicização das informações sobre programas e ações relacionadas a visitação de áreas protegidas no Brasil. Recentemente nota-se uma crescente repercussão do tema fora dos meios tradicionais de comunicação científica (jornalismo ambiental, mídias sociais) em função do crescente interesse popular por atividades de esportes e turismo em contato com a natureza no Brasil. Porém, a emergente produção do conhecimento científico especializado no assunto, publicada sobretudo na forma de resumos expandidos de eventos acadêmicos e poucos artigos completos qualificados de revistas científicas de áreas distintas, tem motivado estudos de forma biogeograficamente fragmentada, concentrada em alguns estados e praticamente ausente em biomas importantes que atualmente enfrentam fortes pressões ambientais naturais e antropogênicas.

$\mathrm{Na}$ sua maioria ações de EA vinculadas a visitação de áreas protegidas documentadas são de cunho acadêmico, realizados na região Sudeste $(60 \%)$, seguidos da região Sul (40\%), Norte de Nordeste (20\%) do Brasil, e nenhum trabalho na região Centro-Oeste, segundo a insituição de origem do primeiro autor, com um protagonismo das Universidades Federais e Estaduais.

A grande maioria dos trabalhos concentra-se no Bioma Mata Atlântica, seguidos unitáriamente pelos demais biomas - Cerrado, Caatinga, Amazônia e Pampa, com a preocupante ausência do bioma Pantanal.

Quanto à categoria e esfera administrativa da área protegida, verifica-se que com exceção de um trabalho realizado no entorno imediato de uma UC, a grande maioria parte dos trabalhos foram realizados em parques sob administração federal ou estadual.

Quanto ao público-alvo verifica-se que a maior parte das pesquisas e ações de Educação Ambiental foram dirigidas a visitantes em geral e estudantes de Educação Básica $(60 \%)$, seguidos por gestores e condutores ambientais (20\%), comunidade técnico-científica e estudantes de Ensino Superior (15\%) e turistas (5,0\%). Quanto à área do conhecimento verifica-se uma preponderância de trabalhos na área da Gestão Ambiental (35\%), Educação Ambiental (30\%), seguidos por Outras (35\%).

Com relação às linhas de atuação, grande parte $(60 \%)$ das ações de EA em áreas protegidas documentadas são convergentes com uma concepção conservacionista (Ecoturismo e condução de visitantes, IA e gestão de impactos ambientais, EA e conservação da biodiversidade, Projetos escolares e ambientalização curricular) e outra parcela menor (40\%) das ações convergentes com uma concepção socioambiental (Extensão e capacitação em gestão ambiental, Geoconservação e EA, Uso público e gestão participativa de UCs, Planejamento de trilhas interpretativas). Um tópico essencial identificado, que porém não atendeu ao critério temporal, foi o uso de Tecnologias de informação e comunicação para EA em UCs.

Revbea, São Paulo, V. 17, № 1: 247-270, 2022. 
A produção do conhecimento no tema permitiu identificar que, com exceção das RPPNs e poucos Parques Nacionais ou Estaduais que recebem uma grande afluência de visitação turística, o conjunto de fontes analisados revelam a fragilidade da regulamentação e estruturação para o uso público de UCs, e a carência de ações de IA e EA associadas à programas de visitação. Quando existem, tais ações retratam experiências pontuais de EA não-formal vinculadas à programas de visitação (em boa parte relacionadas às exigências de formação ou capacitação de guias/condutores de turismo e gestores ambientais), dirigidas ainda majoritariamente ao público visitante (não-morador do entorno) e estudantes (Ens. Médio/Técnico) das redes pública e privada, focadas primariamente no turismo e recreação, e subsidiariamente na EA.

Com exceção de algumas experiências notáveis de protagonismo e articulação em rede dos stakeholders (mídias sociais digitais, instituições de ensino/pesquisa, órgãos de meio ambiente/turismo, escolas parceiras, associações de condutores de turismo, grupos voluntários e comunidades de prática), a maior parte das ações documentadas foram de pesquisa documental ou social aplicada, descritiva, pouco explicativa. Percebe-se, contudo, alguns esforços notáveis de desenvolvimento teórico-metodológico conceitual e procedimental voltado para ações educativas na gestão pública de áreas protegidas, que ainda carecem de qualificação da formação de recursos humanos para a desejada integração - de forma transversal, interdisciplinar e participativa -, dessas práticas de IA/EA com conteúdos curriculares da Educação Básica e conteúdos socioambientais da gestão desses espaços públicos.

\section{Referências}

BRAGA, R. De B. R. M; MEIRELLES, R. De S. M; SIQUEIRA, A. de E. Considerações teóricas para prática da EA no Parque Estadual da Tijuca-RJ: concepções e práxis dos visitantes, Anais do IX -Encontro Pesquisa em Educação Ambiental - 13 a 16 de agosto - 2017, Juiz de Fora: UFJF, [s.p], 2017.

BUENO, C. et al. Ecoturismo Responsável e seus Fundamentos. 1aㅡ Ed, Rio de Janeiro: Technical Books, 2011, 256p.

CANTO-SILVA, C. R; SILVA, J. Da S. Panorama da visitação e da condução de visitantes em Parques brasileiros. Rev. Bras. Pesq. Tur., São Paulo, v.11, n.2, p.347-364, maio/ago., 2017.

CHAVES, T. C. De O. et al. Programa Parque Escola: uso público nas Unidades de Conservação em Gupimirim-RJ. Revista Eletrônica Uso Público em Unidades de Conservação, Niterói, v.3, n.7, p.74-84, 2015. 
CORRÊA, L. R; FOLETO, E. M; COSTA, F. Da S. Interpretação ambiental através dos programas de uso público das Reservas Particulares do Patrimônio Natural Federais. Revista do PPGEA/FURG-RS, v.37, n.1, p.166-187, jan./abr., 2020.

ENGERS, F.M; KONRATH, J.D. Trilha interpretativa autoguiada do Parque Natural Municipal da Ronda - Caminho das Araucárias/RBT, São Francisco de Paula-RS: um longo percurso de Ensino, Pesquisa e Extensão pela visitação de áreas protegidas. e-Book. Porto Alegre: Imageambiente/Ganeco-UERGS, 2021, 38p.

ENGERS, F.M; COMUNELLO, L; KONRATH, J. Intervenções socioambientais por meio de trilhas interpretativas em UCs da região dos Campos de Cima da Serra-RS. Anais do IX Salão Integrado de Ensino, Pesquisa e Extensão SIEPEX, 28 de maio - 2019. UERGS: Rio Grande do Sul, [s/p]. Disponível em: $<$ http://conferencia.uergs.edu.br/index.php/IXSIEPEX/IXSIEPEX/paper/view/35 30> Acesso em: $1^{\circ} \mathrm{dez} .2020$.

FRIZZO, T. C.E; GONÇALVES, P. S; SOUZA, B. De R. Escolas e unidades de conservação: aproximações e desafios em Itapuã, Viamão, RS. Anais do $X$ Encontro de Pesquisa em Educação Ambiental/VII ESEA Encontro Sergipano de Educação Ambiental - 14 de setembro - 2019, São Cristóvão: UFS, [s.p.] 2019.

GEOPARQUE CÂNIONS DO SUL. Projeto Geoparque Caminhos dos Cânions do Sul. Disponível em: <https://canionsdosul.org/conheça> Acesso em: 01 dez. 2020.

GIL, A. C. Métodos e técnicas de pesquisa social. 5ed. São Paulo: Atlas, 1999, 206p.

LOUREIRO, C. F. B; SAISSE, M. Educação Ambiental na gestão ambiental pública brasileira: uma análise da SEMA ao ICMBio. Revista Educação Pública, Cuiabá, v.23, n.52, p.105-129, 2014.

MARQUES, K. F. (org). In: Secretaria do Meio Ambiente e Infraestrutura. Anais do $1^{\circ}$ Encontro da Rede SEIVA - Socialização, Identidade, Vida e Ambiente: Educação Ambiental em Unidades de Conservação - 02 de dezembro - 2017, São Francisco de Paula: SEMA-RS/PMSFP [s.p], 2017. Disponível em: $<$ https://www.sema.rs.gov.br/sema-promove-evento-para-comunidade-escolarsobre-unidades-de-conservacao $>$. Acesso em: $1^{\circ}$ dez. 2020.

MATOS, B. C. S; FERREIRA, M. P. S; ZAMPIERON, S. L. M. Formação de agentes disseminadores do processo de educação para unidades de conservação, com ênfase no Parque Nacional da Serra da Canastra. Em Extensão, Uberlândia, v.16, n.1, p.97-114, jan./jun., 2017.

MUNHOZ, B. E. M. et al. A função socioambiental da educação e da interpretação ambiental na conservação do patrimônio ambiental em SC. Acta Biológica Catarinense, jan./mar., v.6, n.1 p.58-67, 2019. 
OECO. 0 que pensam os brasileiros sobre áreas protegidas e 0 meio ambiente segundo pesquisa do IBOPE (2018). Disponível em: $<$ https://www.oeco.org.br/blogs/salada-verde/mais-de-90-dos-brasileiros-gosta riam-de-ter-mais-contato-com-a-natureza-diz-ibope> Acesso em: $1^{\circ} \mathrm{dez} .2020$.

OLIVEIRA, C. De N. et al. Contribuições para o desenvolvimento da Educação Ambiental em Unidades de Conservação a partir de programas educativos do Geoparque Naturtejo. TERRAE (PT) n.11, p.03-14, 2014.

OMENA, M. T. De R.N; BREGOLIN, M. A Importância das Trilhas Regionais para RBTLC. Ambiente \& Sociedade, São Paulo, v.23. p.1-21, 2020.

PEREIRA, I. D. D. S; SOUZA, I. De S; LINHARES, T. Dos S. Educação Ambiental interdisciplinariedade através de aula de campo sobre o bioma Mata Alântica. Anais do 5 Simpósio de Gestão Ambiental e Biodiversidade - 21 a 23 de junho - 2016, UFF: Rio de Janeiro, p.469-474, 2016.

PEDRINI, A. G. Trilhas interpretativas no Brasil - uma proposta para o ensino básico. AmbientalMENTEsustentable, v.25, n.1, p.77-115, jan./jun., 2018.

PIMENTEL, D. D. S. et al. Desafios e avanços para estruturação de uma comunidade de prática de visitação em áreas protegidas. Revista Eletrônica Uso Público em Unidades de Conservação. Niterói, v. 7, n. 11. p: 63-78. 2019.

PROCHNOW, M. Natureza: Parques e Reservas Naturais. 2018. (17m40s). Disponível em:https://www.youtube.com/watch?v=e7|KZfuMytY> Acesso em: $1^{\circ}$ dez. 2020.

RECH, I. F; PERELLO, L. Fernando C; CANTO-SILVA, C. R. Panorama do uso público em parques estaduais do Rio Grande do Sul. Revista Brasileira de Ecoturismo, São Paulo, v.10, n.4, p.919-937, nov./17-jan./18.

REDE ARAUCÁRIAS - Educação Ambiental nos Campos de Cima da Serra e Hortênsias. Constituição de um Geoparque como eixo propulsor da gestão pública em EA no município de Cambará do Sul (Fabiano Souza/SME Cambará do Sul). 2020. Disponível em: <https://sites.google.com/view/ redearaucarias $/ \mathrm{p} \% \mathrm{C} 3 \% \mathrm{~A} 1$ gina-inicial? authuser $=0>$ Acessado em: 01 de dezembro de 2020.

RIO DE JANEIRO. Mapa de azuleijos da Floresta da Tijuca, Rio de JaneiroRS. Disponível em: <https://www.riodejaneiroaqui.com/figuras1/ mapa-florestatijuca-em-painel-de-azulejos.jpg > Acesso: 17.07.2021.

SOUZA, F. (coord). Constituição de um Geoparque como eixo propulsor da gestão pública em EA no município de Cambará do Sul. In: REDE ARAUCARIAS - Educação Ambiental nos Campos de Cima da Serra e Hortênsias. Disponível em:<https://sites.google.com/view/redearaucarias/p\% C3\%A1gina-inicial?authuser $=0$ > Acesso em: $1^{\circ} \mathrm{dez} .2020$. 
REINEHR, R. (coord). 1 Encontro Estadual Educação e Ambiente: Temas Transversais em Redes Ambientais. In: BINKOWSKI, Patrícia et al. III Simpósio de Gestão Ambiental da UERGS: Territórios Hídricos e Mercados Ambientais. São Francisco de Paula, 7/abril, 2017. Revista Eletrônica Científica da UERGS, v.3, n.4 (Númeo Especial), p.668-673, 2017.

RODRIGUES, L. M; CAMPANHÃO, L. M. B; BERNARDI, I. R. Tendências político-pedagógicas de Educação Ambiental em unidades de conservação: o caso dos Parques Estaduais de SP. Revista Brasileira de Educação Ambiental, São Paulo, v.13, n.1, p.192-212, 2018.

SANTOS, J. Dos L; AZEVEDO, S. De C., Educação Ambiental nos Parques Nacionais Brasileiros: a distância entre a lei e a prática divulgada, Anais do $X$ Encontro de Pesquisa em Educação Ambiental - 14 de setembro - 2019, São Cristóvão: UFS, [s.p.], 2019.

SANTOS, F. Dos C; RODRIGUES E SILVA, F. A; KATO, D. S. A teoria do atorrede como instrumento para investigar aaprendizagem em rede numa trilha ecológica, Anais do IX -Encontro Pesquisa em Educação Ambiental - 13 a 16 de agosto - 2017, Juiz de Fora: UFJF, [s.p.], 2017.

SHÚ, A.; MARTINEZ, J.; GERHARD, M. A. História ambiental e participação na construção de uma trilha interpretativa. Revista Brasileira de Educação Ambiental, São Paulo, v.15, n.5, p.1-19, 2020.

SILVA, J. Da B.; SILVA, M. C. De P. Educação Ambiental aplicada em Parque Estudal no Pará: uma perspectiva crítica. Revista Geografia Acadêmica, v.11, n.1, p.75-86, 2017.

SILVEIRA, M. Da S; JOBIN, R. R; PROCHNOW, P. Ecoturismo pedagógico no parque natural municipal do Morro do Osso. Revista Eletrônica Uso Público em Unidades de Conservação, Niterói, v.3, n.7, p.23-33, 2015.

SAUVÉ, L. Uma cartografia das correntes em Educação Ambiental. In: SATO, M.; CARVALHO, I.C.M. (Orgs.). Educação Ambiental - pesquisas e desafios. Porto Alegre: Artmed, 2005.

WOLRD WILDLIFE FOUNDATION. Relatório Planeta Vivo - 2018: Uma ambição maior. GROTTEN, M; ALMOND, R.E.A. (Eds). WWF: Gland, Suiça, 2018, 19p. 
Apêndice-1: Quadro-síntese da Produção do Conhecimento sobre Uso Público e Educação Ambiental em Unidades de Conservação do Brasil (2014-2020).

\begin{tabular}{|c|c|c|c|c|c|c|c|}
\hline $\begin{array}{c}\text { Ano e } \\
\text { Região }\end{array}$ & $1^{\circ}$.Autor/l.E & Sub-área & Bioma & $\begin{array}{c}\text { Área } \\
\text { Protegida }\end{array}$ & $\begin{array}{c}\text { Público } \\
\text { abrangido }\end{array}$ & Metodologia de Pesquisa e/ou Ação & Pautas de IA/EA extra-classe \\
\hline \begin{tabular}{l|}
2014 \\
$(\mathrm{BR})$
\end{tabular} & $\begin{array}{l}\text { De Oliveira, } \\
\text { C.N. } \\
\text { UNICAMP }\end{array}$ & $\begin{array}{l}\text { Geociên- } \\
\text { cias }\end{array}$ & Todos & $\begin{array}{l}\text { Geoparque } \\
\text { Naturtejo-PT } \\
\text { vs SNUC-BR }\end{array}$ & $\begin{array}{l}{[\mathrm{s} / \mathrm{d}]} \\
\text { Estudantes } \\
\text { (E.M) }\end{array}$ & 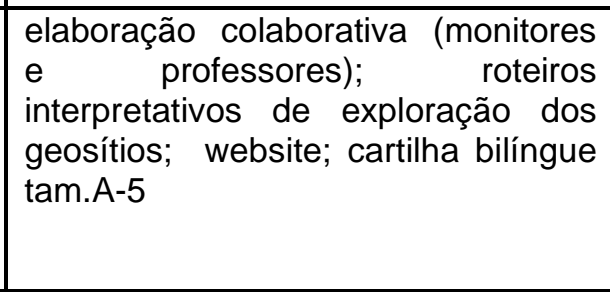 & $\begin{array}{l}\text { geoconservação e desenvolvi } \\
\text { meno territorial sustentaável; } \\
\text { inclusão educativa de comunidades } \\
\text { do entorno; informação e e } \\
\text { comunicação de suporte à EA; } \\
\text { relação entre conteúdos formais e } \\
\text { elementos do ambiente; }\end{array}$ \\
\hline $\begin{array}{l}2015 \\
\text { (BR) }\end{array}$ & $\begin{array}{l}\text { Canto- } \\
\text { Silva, C.R. } \\
\text { IFSul- } \\
\text { P.Alegre }\end{array}$ & Turismo & Todos & $\begin{array}{l}\text { Parques } \\
\text { SNUC-BR }\end{array}$ & $\begin{array}{l}10 \text { mil por } \\
\text { ano } \\
\text { Gestores UCs }\end{array}$ & $\begin{array}{l}\text { pesquisa documental no CNUC-RS; } \\
\text { pesquisa na Internet; consulta aos } \\
\text { planos de manejo; questionários } \\
\text { com gestores das UCs; }\end{array}$ & 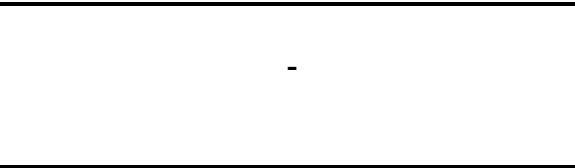 \\
\hline $\begin{array}{l}2015 \\
\text { (SE) }\end{array}$ & \begin{tabular}{l|} 
Chaves, \\
T.C. O. \\
Secr.Meio \\
Amb. \\
Guapimirim \\
-RJ
\end{tabular} & $\begin{array}{l}\text { Gestão } \\
\text { Amb. }\end{array}$ & $\begin{array}{l}\text { Mt.Atlân- } \\
\text { tica }\end{array}$ & $\begin{array}{l}\text { Pq.Nac.S. } \\
\text { Órgãos-RJ } \\
\text { Pq.Est.Três } \\
\text { Picos-RJ } \\
\text { APA de Gua- } \\
\text { pimirim-RJ }\end{array}$ & $\begin{array}{l}360 \text { visitan- } \\
\text { tes em } 1 \text { ano }\end{array}$ & $\begin{array}{l}\text { diagnósitco do uso com } 22 \text { escolas } \\
\text { municipais, sobre o uso de UCs; } \\
\text { elaboração do Programa Parque- } \\
\text { Escola; trilhas guiadas (sem +info); e } \\
\text { atividades recreativas; avaliação } \\
\text { informal por meio de relatos; }\end{array}$ & $\begin{array}{l}\text { UCs como cenários para o ensino } \\
\text { (U.C., uso público, Mata Atlântica, } \\
\text { flora e fauna, impactos e } \\
\text { preservação ambiental); } \\
\text { sensibilização para adoção de } \\
\text { práticas sustentáveis (despejo } \\
\text { resíduos, caça ilegal); }\end{array}$ \\
\hline $\begin{array}{l}2015 \\
\text { (S) }\end{array}$ & $\begin{array}{l}\text { Da Silveira, } \\
\text { M.S. IFSul- } \\
\text { Osório }\end{array}$ & $\begin{array}{l}\text { Gestão } \\
\text { Amb. }\end{array}$ & $\begin{array}{l}\text { Mt.Atlânti- } \\
\text { ca }\end{array}$ & $\begin{array}{l}\text { Pq.Mun. } \\
\text { Morro do } \\
\text { Osso-PoA. }\end{array}$ & $\begin{array}{l}\mathrm{s} / \mathrm{d}] \\
\text { Estudantes } \\
\text { (EF) }\end{array}$ & $\begin{array}{l}\text { visita prévia e palestra às escolas do } \\
\text { entorno; elaboração de roteiro } \\
\text { interpretativo; carta-imagem de } \\
\text { localização da UC e da trilha auto- } \\
\text { guiada pré-existente (s/d distância, } \\
02 \text { h:00 percurso, 18 ptos- } \\
\text { interpretativos) }\end{array}$ & $\begin{array}{l}\text { ecoturismo pedagógico } \\
\text { sensibilização ambiental por meio } \\
\text { de trilha intepretativa (patrimônio } \\
\text { arqueológico, regulação climática, } \\
\text { recurso hídrico, interrupção dos } \\
\text { impactos, recuperação dos campos } \\
\text { e sucessão vegetal); }\end{array}$ \\
\hline $\begin{array}{l}2016 \\
\text { (SE) }\end{array}$ & $\begin{array}{l}\text { Braga, R. } \\
\text { De B.M. }\end{array}$ & $\begin{array}{l}\text { Educ. } \\
\text { Amb. }\end{array}$ & $\begin{array}{l}\text { Mt.Atlân- } \\
\text { tica }\end{array}$ & $\begin{array}{l}\text { Pq.Est..da } \\
\text { Tijuca-RJ }\end{array}$ & $\begin{array}{l}\text { [s/d] } \\
\text { Visitantes e } \\
\text { Estudantes } \\
\text { (ES) }\end{array}$ & $\begin{array}{l}\text { trilha auto-guiada }(876 \mathrm{~m} \text {, } 03 \mathrm{hs}, 05 \\
\text { ptos de IA); pesquisa da história } \\
\text { oral; texto-base da preleção; } \\
\text { avaliação de retenção; }\end{array}$ & $\begin{array}{l}\text { sensibilização ambiental frente aos } \\
\text { impactos humanos; ressignificação } \\
\text { de conceitos e práticas ambientais } \\
\text { dos visitantes; concepção de EA } \\
\text { em UC; }\end{array}$ \\
\hline
\end{tabular}

Continua... 


\begin{tabular}{|c|c|c|c|c|c|c|c|}
\hline $\begin{array}{c}\text { Ano e } \\
\text { Região }\end{array}$ & $\begin{array}{l}\text { 10.Autor/ } \\
\text { I.E }\end{array}$ & Sub-área & Bioma & $\begin{array}{l}\text { Área } \\
\text { Protegida }\end{array}$ & $\begin{array}{l}\text { Público } \\
\text { abrangido }\end{array}$ & $\begin{array}{l}\text { Metodologia de Pesquisa e/ou } \\
\text { Ação }\end{array}$ & Pautas de IA/EA extra-classe \\
\hline $\begin{array}{l}2016 \\
\text { (SE) }\end{array}$ & $\begin{array}{l}\text { Pereira, } \\
\text { da S.D. I. } \\
\text { UFRJ-Rio }\end{array}$ & $\begin{array}{l}\text { Gestão } \\
\text { Amb. }\end{array}$ & $\begin{array}{l}\text { Mt.Atlân- } \\
\text { tica }\end{array}$ & $\begin{array}{l}\text { Pq.Est. do } \\
\text { Desengano } \\
\text {-RJ }\end{array}$ & $\begin{array}{l}\text { [s/d] } \\
\text { Estudantes } \\
\text { (EM) }\end{array}$ & $\begin{array}{l}\text { roteiro } \\
\text { (Hist/Geo/Bio/Qui) das preleções; } \\
\text { aula colaborativa de campo; } \\
\text { avaliação por meio de questionários } \\
\text { e desenhos da trilha (sem +infos). }\end{array}$ & $\begin{array}{l}\text { instrumentalização transversal, } \\
\text { sensibilização ambiental (poluição } \\
\text { do solo, atmosfera e recursos } \\
\text { hídricos, preservação florestal); } \\
\text { estímulo a reflexão crítica; }\end{array}$ \\
\hline $\begin{array}{l}2017 \\
(\mathrm{SE})\end{array}$ & $\begin{array}{l}\text { Dos } \\
\text { Santos, } \\
\text { F.C. } \\
\text { UFOP- } \\
\text { Morro do } \\
\text { Cruzeiro }\end{array}$ & $\begin{array}{l}\text { Educ. } \\
\text { Amb. }\end{array}$ & $\begin{array}{l}\text { Mt.Atlân- } \\
\text { tica/ } \\
\text { Cerrado }\end{array}$ & $\begin{array}{l}\text { Est.Ecol. da } \\
\text { UFMG }\end{array}$ & $\begin{array}{l}\text { [s/d] } \\
\text { Estudantes } \\
(\mathrm{EF})\end{array}$ & $\begin{array}{l}\text { elaboração de sequência didática; } \\
\text { aprendizagem do ambiente; } \\
\text { investigação por meio da teoria do } \\
\text { Ator-Rede; de trilha guiada (5 ptos. } \\
\text { de IA, sem +infos). }\end{array}$ & $\begin{array}{l}\text { estudo do meio e aprendizagem } \\
\text { extra-classe (história ambiental, } \\
\text { transição de biomas, inter-relações } \\
\text { abio/bióticas/huma-r nas); } \\
\text { necessidade de preservação; }\end{array}$ \\
\hline $\begin{array}{l}2017 \\
\text { (SE) }\end{array}$ & $\begin{array}{l}\text { Matos, } \\
\text { B.C.S. } \\
\text { UEMG- } \\
\text { Passos }\end{array}$ & Ext.Rural & $\begin{array}{l}\text { Mt.Atlânti- } \\
\text { ca }\end{array}$ & $\begin{array}{l}\text { Pq.Nac. } \\
\text { Serra da } \\
\text { Canastra- } \\
\text { MG }\end{array}$ & $\begin{array}{l}15 \\
\text { estudantes } \\
\text { em } 1 \text { ano } \\
\text { (EM) }\end{array}$ & $\begin{array}{l}\text { curso de formação de condutores } \\
\text { ambientais locais; elaboração de } \\
\text { blog e apostila; aulas teóricas; aula } \\
\text { prática; trilha guiada (s/dist, 03hs, } \\
\text { sem +infos). }\end{array}$ & $\begin{array}{lrr}\begin{array}{l}\text { Capacitação } \\
\text { visitantes }\end{array} & \begin{array}{l}\text { para } \\
\text { (E.A., }\end{array} & \begin{array}{r}\text { condução de } \\
\text { ecoturismo; }\end{array} \\
\text { sustentabilidade, } & \text { fauna e flora; } \\
\text { geolocalização, } & \text { segurança); } \\
\text { problematização } & \text { (aspectos } \\
\text { positivos/negativos do turismo, his- } \\
\text { tórico de conflitos. }\end{array}$ \\
\hline $\begin{array}{c}2017 \\
(\mathrm{~N})\end{array}$ & $\begin{array}{l}\text { Da Silva, } \\
\text { J.B. } \\
\text { UFPA }\end{array}$ & $\begin{array}{l}\text { Geociên- } \\
\text { cias }\end{array}$ & Amazônia & $\begin{array}{l}\text { Pq.Est.de } \\
\text { Utinga-PA }\end{array}$ & $\begin{array}{l}\mathrm{s} / \mathrm{d}] \\
\text { Visitantes }\end{array}$ & $\begin{array}{l}\text { Projeto de EA e } \begin{array}{r}\text { Saneamento; } \\
\text { monitorada; }\end{array} \\
\text { sequência-didática } \\
\text { cartilha educativa; visita técnica } \\
\text { guiada à ETA; trilha-interpretativa } \\
\text { guiada (sem +infos); }\end{array}$ & $\begin{array}{l}\text { transmissão de informações; } \\
\text { respeito às legislação ambiental; } \\
\text { sensibilização individual; boas } \\
\text { práticas de uso dos recursos (água, } \\
\text { vegetação ciliar, ambiente } \\
\text { lacustre); }\end{array}$ \\
\hline $\begin{array}{l}2017 \\
(\mathrm{~S})\end{array}$ & $\begin{array}{l}\text { Reinher, } \\
\text { R. } \\
\text { UERGS- } \\
\text { S.F.Paula }\end{array}$ & $\begin{array}{l}\text { Gestão } \\
\text { Amb. }\end{array}$ & $\begin{array}{l}\text { Mt.Atlânti- } \\
\text { ca/C.Sulino } \\
\text { s }\end{array}$ & $\begin{array}{l}\text { UCs dos } \\
\text { Campos de } \\
\text { Cima da } \\
\text { Serra-RS. }\end{array}$ & $\begin{array}{l}\text { [s/d] } \\
\text { Professores } \\
\text { e } \\
\text { Estudantes } \\
\text { (EB) }\end{array}$ & $\begin{array}{l}\text { 10.Encontro Estadual Educação e } \\
\text { Ambientes; instituição da Rede } \\
\text { Araucárias de EA da Região dos } \\
\text { Campos de Cima da Serra }\end{array}$ & - \\
\hline $\begin{array}{c}2018 \\
(\mathrm{~S})\end{array}$ & $\begin{array}{l}\text { Rech, I.F. } \\
\text { IFSul- } \\
\text { Po.A. }\end{array}$ & $\begin{array}{l}\text { Ecoturis- } \\
\text { mo }\end{array}$ & $\begin{array}{l}\text { Mt.Atlânti- } \\
\text { ca } \\
\text { Pampa }\end{array}$ & $\begin{array}{l}\text { Parques } \\
\text { SEUC-RS }\end{array}$ & $\begin{array}{l}14 \text { gestores } \\
\text { Gestores de } \\
\text { UCs }\end{array}$ & $\begin{array}{l}\text { Pesquisa documental no SEUC-RS; } \\
\text { consulta documental aos planos de } \\
\text { manejo e entrevistas com gestores; }\end{array}$ & - \\
\hline
\end{tabular}




\begin{tabular}{|c|c|c|c|c|c|c|c|}
\hline $\begin{array}{l}\text { Ano e } \\
\text { Região }\end{array}$ & $1^{\circ}$. Autor/I.E. & $\begin{array}{l}\text { Sub- } \\
\text { área }\end{array}$ & Bioma & $\begin{array}{c}\text { Área } \\
\text { Protegida }\end{array}$ & $\begin{array}{c}\text { Público } \\
\text { abrangido }\end{array}$ & Metodologia de Pesquisa e/ou Ação & Pautas de IA/EA extra-classe \\
\hline $\begin{array}{l}2018 \\
(\mathrm{SE})\end{array}$ & $\begin{array}{l}\text { Rodrigues, } \\
\text { L.M. } \\
\text { UFSCar }\end{array}$ & $\begin{array}{l}\text { Educ. } \\
\text { Amb. }\end{array}$ & $\begin{array}{l}\text { Mt.Atlânti- } \\
\text { ca } \\
\text { Cerrado }\end{array}$ & $\begin{array}{l}\text { Parques } \\
\text { SECU-SP }\end{array}$ & $\begin{array}{l}30 \\
\text { gestores } \\
\text { Gestores } \\
\text { de UCs }\end{array}$ & $\begin{array}{l}\text { pesquisa documental no SNUC-BR; } \\
\text { consulta aos planos de manejos dos } \\
\text { parques; entrevistas com gestores; } \\
\text { visitas técnicas às UCs; }\end{array}$ & - \\
\hline $\begin{array}{c}2018 \\
(\mathrm{~S})\end{array}$ & $\begin{array}{l}\text { Pedrini, G.A. } \\
\text { UFRJ }\end{array}$ & $\begin{array}{l}\text { Educ. } \\
\text { Amb. }\end{array}$ & $\begin{array}{l}\text { Mt.Atlânti- } \\
\text { ca } \\
\text { Z.Costeira }\end{array}$ & SNUC-BR & $\begin{array}{l}20 \\
\text { autores e } \\
\text { pesquisado } \\
\text {-res }\end{array}$ & $\begin{array}{l}\text { elaboração de um roteiro básico de } \\
\text { apoio à condução de estudantes da } \\
\text { E.Básico em trilhas interpretativas, } \\
\text { para diferentes ambientes; }\end{array}$ & - \\
\hline $\begin{array}{l}2018 \\
(\mathrm{BR})\end{array}$ & $\begin{array}{l}\text { [sem autor] } \\
\text { IBOPE }\end{array}$ & $\begin{array}{l}\text { Meio } \\
\text { Amb. }\end{array}$ & Todos & $\begin{array}{l}\text { Áreas } \\
\text { protegidas-BR } \\
\text { (sensu lato) }\end{array}$ & $\begin{array}{l}9 \text { mil } \\
\text { habitan-tes }\end{array}$ & $\begin{array}{l}\text { pesquisa de opinião pública sobre "o } \\
\text { que pensam os brasileiros sobre } \\
\text { áreas protegidas e meio ambiente"; }\end{array}$ & 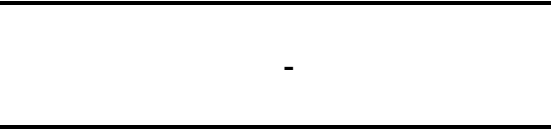 \\
\hline $\begin{array}{l}2018 \\
(\mathrm{RS})\end{array}$ & $\begin{array}{l}\text { Rede } \\
\text { Araucárias } \\
\text { UERGS- } \\
\text { S.F.Paula }\end{array}$ & $\begin{array}{l}\text { Educ. } \\
\text { Amb. }\end{array}$ & $\begin{array}{l}\text { Mt.Atlânti- } \\
\text { ca } \\
\text { C.Sulinos }\end{array}$ & $\begin{array}{l}\text { Pq.s Nac.s } \\
\text { Aparados-e } \\
\text { S.Geral-RS-SC } \\
\text { Pq.Est. } \\
\text { Tainhas }\end{array}$ & $\begin{array}{l}22 \text { escolas } \\
\text { Professore } \\
\text { s e } \\
\text { Estudantes } \\
\text { (EB) }\end{array}$ & 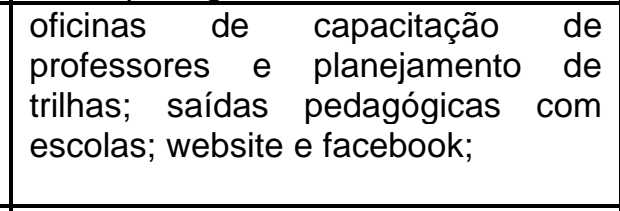 & $\begin{array}{l}\text { ações de EA em rede; formação } \\
\text { ecopedagógica; educação para } \\
\text { sustentabilidade; políticas públicas } \\
\text { em EA e conservação da } \\
\text { biodiversidade; }\end{array}$ \\
\hline $\begin{array}{l}2019 \\
(\mathrm{BR})\end{array}$ & $\begin{array}{l}\text { Pimentel, } \\
\text { D.S.D. } \\
\text { UM- } \\
\text { EUA/UFRJ }\end{array}$ & $\begin{array}{l}\text { Soc. \& } \\
\text { Amb. }\end{array}$ & Todos & SNUC-BR & $\begin{array}{l}\text { [s/d] } \\
\text { Pesquisad } \\
\text { ores } \\
\text { Gestores } \\
\text { UCs }\end{array}$ & $\begin{array}{l}\text { formação de uma comunidade } \\
\text { (virtual) de prática sobre visitação de } \\
\text { UCs (EUA/BR); seminários regionais } \\
\text { sobre pesquisa e visitação de UCs; } \\
\text { e-mídia social. }\end{array}$ & 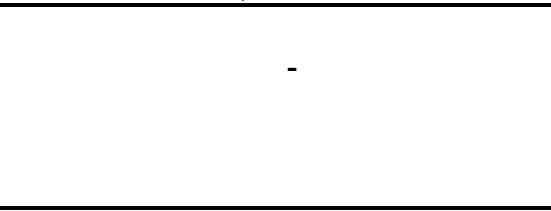 \\
\hline $\begin{array}{c}2019 \\
(\mathrm{~S})\end{array}$ & $\begin{array}{l}\text { Munhoz, } \\
\text { E.M.B. } \\
\text { UNIVILLE }\end{array}$ & $\begin{array}{l}\text { Educ. } \\
\text { Amb. }\end{array}$ & $\begin{array}{l}\text { Mt.Atlânti- } \\
\text { ca } \\
\text { Z.Costeira }\end{array}$ & $\begin{array}{l}\text { CPEA-S. } \\
\text { Francisco } \\
\text { CPEA-S.Bento } \\
\text { do Sul } \\
\text { Jd.Botânico da } \\
\text { UNIVI-LLE } \\
\end{array}$ & $\begin{array}{l}\text { [s.d] } \\
\text { Professore } \\
\text { s e } \\
\text { Estudantes } \\
\text { (EB) }\end{array}$ & $\begin{array}{l}\text { programa de extensão universitária; } \\
\text { formação de professores; } \\
\text { capacitação de condutores; trilhas } \\
\text { interpretativas monitoradas; }\end{array}$ & $\begin{array}{l}\text { educação socioambiental; ação } \\
\text { pedagógica em educação para } \\
\text { sustentabilidade; aprendizagem } \\
\text { lúdica; sensibilização ambiental; }\end{array}$ \\
\hline $\begin{array}{l}2019 \\
(\mathrm{BR})\end{array}$ & $\begin{array}{l}\text { Dos Santos, } \\
\text { L.J. } \\
\text { UNIFAL }\end{array}$ & $\begin{array}{l}\text { Educ.A } \\
\text { mb. }\end{array}$ & Todos & $\begin{array}{l}\text { Parques } \\
\text { SNUC-BR }\end{array}$ & $\begin{array}{l}74 \\
\text { gestores } \\
\text { Gestores } \\
\text { de UCs }\end{array}$ & $\begin{array}{l}\text { pesquisa documental no CNUC; } \\
\text { questionário eletrônico com gestores } \\
\text { das UCs; pesquisa sobre divulgação } \\
\text { das UCs na Internet; }\end{array}$ & - \\
\hline
\end{tabular}




\begin{tabular}{|c|c|c|c|c|c|c|c|}
\hline $\begin{array}{c}\text { Ano e } \\
\text { Região }\end{array}$ & $1^{\circ}$. Autor/l.E. & $\begin{array}{l}\text { Sub- } \\
\text { área }\end{array}$ & Bioma & $\begin{array}{c}\text { Área } \\
\text { Protegida }\end{array}$ & $\begin{array}{c}\text { Público } \\
\text { abrangido }\end{array}$ & Metodologia de Pesquisa e/ou Ação & Pautas de IA/EA extra-classe \\
\hline $\begin{array}{c}2020 \\
(S)\end{array}$ & $\begin{array}{l}\text { Schú, A. } \\
\text { URI-Erechim }\end{array}$ & $\begin{array}{l}\text { Educ. } \\
\text { Amb. }\end{array}$ & $\begin{array}{l}\text { Mt.Atlânti- } \\
\text { ca } \\
\text { C.Sulinos }\end{array}$ & $\begin{array}{l}\text { PNM João } \\
\text { A.X.da Cruz }\end{array}$ & $\begin{array}{l}35 \text { colabora- } \\
\text { dores } \\
\text { Participantes }\end{array}$ & $\begin{array}{l}\text { pesquisa de história oral; elaboração } \\
\text { de roteiro-interpretativo; trilha-guiada } \\
\text { (s/d distância; } 01 \mathrm{~h}: 30 ; 9 \text { ptos); teste- } \\
\text { piloto de avaliação da efetividade; }\end{array}$ & $\begin{array}{l}\text { resgate da identidade cultural; } \\
\text { história ambiental e } \\
\text { sustentabilidade; significações } \\
\text { atribuídas ao Parque; }\end{array}$ \\
\hline $\begin{array}{l}2020 \\
\text { (BR) }\end{array}$ & $\begin{array}{l}\text { Corrêa, R.L. } \\
\text { UFSM }\end{array}$ & $\begin{array}{l}\text { Educ. } \\
\text { Amb }\end{array}$ & $\begin{array}{l}\text { Mt.Atlânti- } \\
\text { ca }\end{array}$ & $\begin{array}{l}\text { RPPNs } \\
\text { Federais } \\
\text { SNUC-BR }\end{array}$ & $\begin{array}{l}56 \text { gestores } \\
\text { Gestores da } \\
\text { UCs }\end{array}$ & $\begin{array}{l}\text { pesquisa documental no SNUC; } \\
\text { entrevistas com gestores das } \\
\text { RPPNs; visitas técnicas; }\end{array}$ & - \\
\hline $\begin{array}{l}2020 \\
\text { (S) }\end{array}$ & $\begin{array}{l}\text { Geoparque } \\
\text { Caminho } \\
\text { dos Cânions } \\
\text { do Sul }\end{array}$ & $\begin{array}{l}\text { Geotu- } \\
\text { rismo }\end{array}$ & $\begin{array}{l}\text { Mt.Atlânti- } \\
\text { ca } \\
\text { C.Sulinos }\end{array}$ & $\begin{array}{l}\text { Geoparque } \\
\text { Cânions do } \\
\text { Sul-Aspi- } \\
\text { rante }\end{array}$ & $\begin{array}{l}12 \text { mil estu- } \\
\text { dantes [s/d] } \\
\text { professores } \\
\text { (EB), em } 2 \\
\text { anos }\end{array}$ & $\begin{array}{l}\text { implementação de } \text { um } \text { consórcio } \\
\text { intermunicipal } \\
\text { Cânions do pró-Geoparque } \\
\text { regionais sul; seminários } \\
\text { exposição itinerante; website; }\end{array}$ & $\begin{array}{llr}\text { geoconservação } & \text { e } & \text { turismo } \\
\text { sustentável; } & \text { vivência } & \text { e } \\
\text { aprendizagem na natureza; } & \text { na nace } \\
\text { divulgação do SEUC-RS; difusão } \\
\text { científica do patrimônio natural e } \\
\text { cultural; }\end{array}$ \\
\hline \multicolumn{2}{|c|}{ 10.Autor } & \multicolumn{6}{|c|}{ Trabalhos selecionados contemplados somente na analise descrtiva } \\
\hline \multicolumn{2}{|c|}{ VALEJJO, L.R. } & \multicolumn{6}{|c|}{$\begin{array}{l}\text { Uso público em áreas protegidas: atores, impactos, diretrizes de planejamento e gestão. Anais do Encontro Fluminense sobre } \\
\text { Uso Público em Unids. Conserv., Niterói,, } 23-25 \text { de julho }-2013 \text {, p. } 13-26 \text {. }\end{array}$} \\
\hline \multicolumn{2}{|c|}{ QUINTANILHA, L. } & \multicolumn{6}{|c|}{$\begin{array}{l}\text { Uso públio em áreas protegidas -um roteiro de atividades para fortalecimento de vivências através da EA. Revta. Anais do Uso } \\
\text { Público em Unids. Conserv., Niterói, v.2, n.2, p.10-19, } 2014 \text {. }\end{array}$} \\
\hline \multicolumn{2}{|c|}{ MONTEIRO, G. M. } & \multicolumn{6}{|c|}{$\begin{array}{l}\text { A importância da Educação Ambiental em UCs: Caso Pq. Nat.Mun. de Marapendi. Anais do 5ㅇ Simpósio de Gestão Ambiental } \\
\text { e Biodiversidade, Rio de Janeiro, } 21 \text { a } 23 \text { de junho - 2016, p. 402-405. }\end{array}$} \\
\hline \multicolumn{2}{|c|}{ HENRIQUE, S. } & \multirow{2}{*}{\multicolumn{6}{|c|}{$\begin{array}{l}\text { A contribuição das trilhas interpretativas no processo de formação de gestores ambientais. Anais do 50 Simpósio de Gestão } \\
\text { Ambiental e Biodiversidade, Rio de Janeiro, } 21 \text { a } 23 \text { de junho - } 2016, \text { p. } 461-468 \text {. } \\
2016.69 f \text {. Interpretação ambiental, aspectos biológicos e educacionais do Pq. Est. da Costa do Sol e da APA do Pau-Brasil- } \\
\text { RJ. TCC (Mestrado Profissional) - Curso de Especialização em Educação Ambiental, Inst. Pesq. Jd. Botânico, Rio de Janeiro, } \\
\text { 2016. }\end{array}$}} \\
\hline \multicolumn{2}{|c|}{ SALEME, F. } & & & & & & \\
\hline \multicolumn{2}{|c|}{$\begin{array}{l}\text { DELGADO-MENDEZ, } \\
\text { J.M. }\end{array}$} & \multicolumn{6}{|c|}{$\begin{array}{l}\text { A interpretação ambiental como instrumento de gestão ambiental de unidades de conservação. Rev. Eletr. Uso Público em } \\
\text { Unids. Conserv., Niterói, v. } 6, \text { n. } 10, \text { p. } 42-54.2018 \text {. }\end{array}$} \\
\hline
\end{tabular}

